\title{
INTEGRATED SURVEY AND SMART NAVIGATION OF COMPLEX TERRITORIAL MODELS
}

\author{
M. Liuzzo, D. Caraccio, E. Di Maggio, G. Luca \\ Kore University of Enna, Italy \\ (mariangela.liuzzo@unikore.it, dario.caraccio@unikorestudent.it, egidio.dimaggio@unikore.it, gianpiluca@hotmail.it)
}

\section{Commission II}

KEY WORDS: Integrated Survey, 3d Laser Scanning, Aerial Photogrammetry, 3D Modelling, Virtual Reality, Complex Sites.

\begin{abstract}
:
The study examines the numerous medieval fortified sites that are in ruins throughout the Sicilian territory. Their landscape and historical value is significant, but they are unfortunately abandoned, not in stable conditions and often no metrically reliable graphic representation exists.

The methodology we chose required a combined 3D survey campaign and data processing aimed at obtaining 2D and 3D drawings, as well as a virtual reality application to provide knowledge and virtual fruition of the sites.

The entire experimental procedure was optimised to provide multi-scalar readings of the sites under investigation, that include their details, the location, territory, and landscape.

The article presents the results of a case study carried out on the Maletto Castle in Sicily (Italy).
\end{abstract}

\section{INTRODUCTION}

Technology today allows us to study artefacts and portions of a territory that were once impossible to reach due to the difficulties linked to surveying and representation. The current survey instruments and data elaboration software help us manage these difficulties and allow us to evaluate the best combination of technology to be used that is also the most costeffective. We consider all of the various features of the instruments and software available, to align the technological options with the specific cultural requests and knowledge instances.

This study focuses on the need to investigate numerous culturally significant locations around our territory. These sites are characterized by the presence of fragmented elements or traces (architectural, archaeological and sculptural) inside areas of high scenic value that are not easily surveyable or visitable and are often in a dire state of abandonment.

The objective is to help return these sites to their communities. We provide a methodological approach based on scientific knowledge, intuitive sharing and culturally oriented enjoyment of the sites' peculiarities.

We applied this approach to the Maletto Castle located in the nearby orographic and urban setting and within the larger landscape of the Etna volcano in Sicily.

\section{RELATED WORKS}

The evolution of this kind of study emerged within the scientific literature. Its development has come about in recent years due in part to the new possibilities that the innovative technology found within the sector offers.

We reference survey campaigns in complex locations, characterized by the dual presence of both natural and anthropic elements (Remondino, 2011; Girelli et al., 2017; HerreroTejedor et al., 2020; Liuzzo and Giuliano, 2019; Liuzzo et al., 2017, 2019).
By overcoming the debate around image vs range-based methods, we were able to combine both methods of technology to take advantage of their potential and minimize their limitations. The recent progress and simultaneous diffusion, with relatively contained costs, of unmanned aerial vehicles, GPS and software surrounding this sector made it possible to obtain efficient three-dimensional models of such complex areas while limiting the cost and time needed (Jo and Kim 2017; Liuzzo et al., 2020; Versaci et al., 2020; Valenti and Paternò, 2021).

The numerous VR and AR applications aimed at the compelling and interactive storytelling of the museums and places of interest were additional areas of study (Canciani et al., 2016; Helle et al., 2017; Mongiello et al., 2018; Teruggi et al., 2021; Spallone et al., 2021).

\section{THE CASE STUDY OF THE MALETTO CASTLE}

The territory of Maletto is located on the slopes of Mount Etna, in Sicily. It is possible to define a route that connects its castle to the other fortifications of the so-called Frederician Etna Route (Figure 1), since Frederick II of Swabia was the promoter of the construction or transformation of this fortified system around the volcano (Alibrandi and Signorello, 1988).

In particular, Maletto was the defence point for the nearby town of Randazzo, which was a residence for the Aragonese kings and a strategic point in the control of the communication route between Palermo and Messina (Nibali and Luca, 1983).

The castle never achieved great importance and a violent earthquake in 1693 damaged its structure, leading to its abandonment. Subsequently, the monument became the object of acts of looting, and in the 17th century, it became a place of refuge for fugitives. Finally, in 1908 another strong earthquake caused the last remains to collapse.

Its landscape value, however, remains intact. The castle sits on a high rock, which is inaccessible. The only access point is on the northern side of the rock where the town of Maletto is located, as the slope is less steep. 

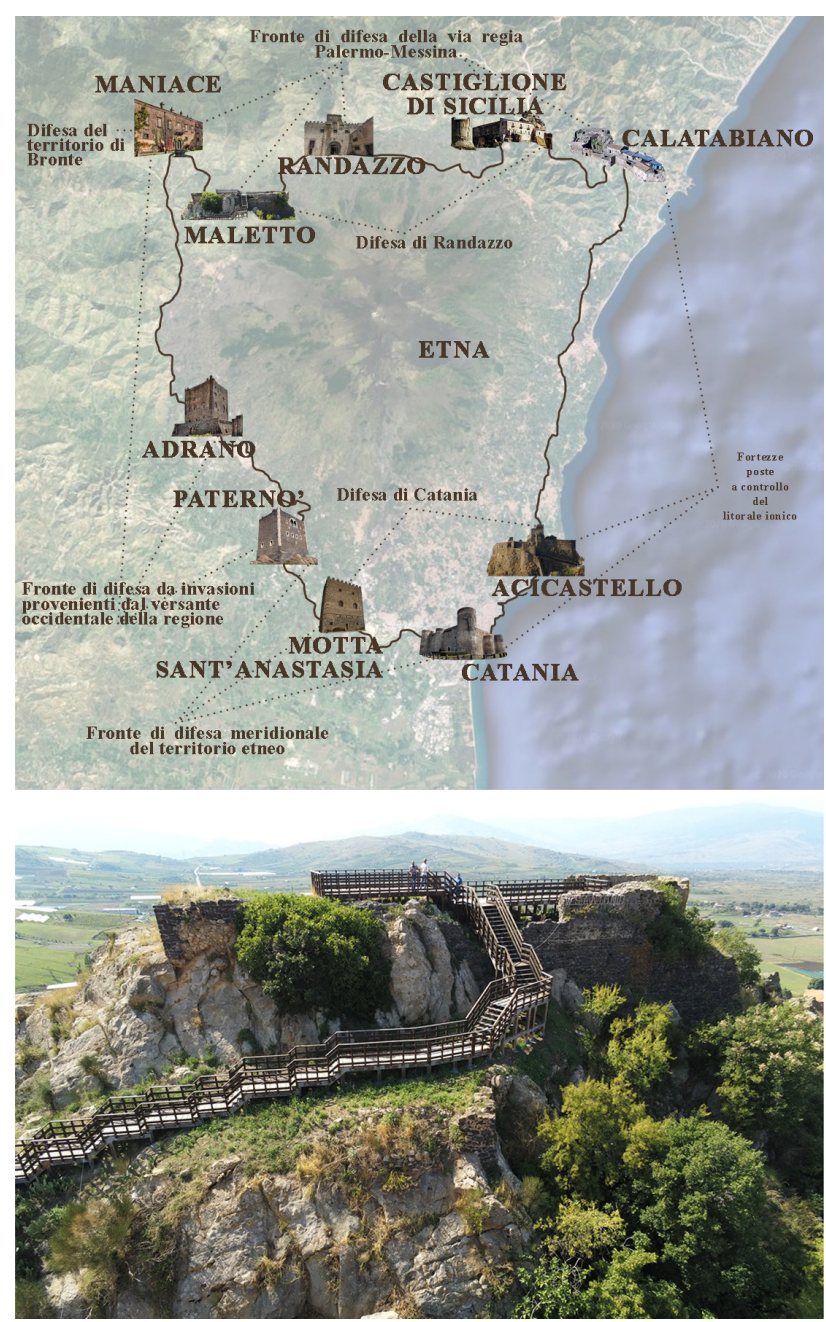

Figure 1. The so called Frederician Etna Route and the Maletto Castle, in Sicily (Italy).

The remains of the castle that have survived to the present day do not allow for distinct architectural analysis, but they allow the identification of three construction phases. The first phase concerns the upper part of the castle, which has a rectangular layout and has three large rooms. This part most likely dates back to the foundation of the castle in 1263 . These may have included a chapel and a turret.

The second phase is represented by an angular wall surrounding the summit building. The rest is occupied by an esplanade partly bordered by two sections of a lesser quality wall, which can be traced back to a third construction phase.

The castle is in complete ruins, and the rock has stability issues. The site is not easily accessible due in part to the steep altitude difference. A recent wooden staircase makes it possible to reach the top, where a large platform provides a beautiful panoramic view. This access system has hidden the traces of the original stairway, which was carved into the rock, contributing to erasing the historical memory of the site (Figure 1).

\section{METHODOLOGICAL APPROACH}

The case study chosen for this paper is part of a wide-ranging experimentation aimed at the study of numerous fortification sites that are in ruins throughout the Sicilian territory (Liuzzo et al., 2020).
Often, these locations are characterized by the near-total devastation of their physical structure yet remain, to this day, reference points for the territory. They can be considered custodians of the historical memory and recognized as the symbol of the local identity.

These sites are located at the peak of inhabited areas and are linked by a similar loss of function and material structure. Contrarily though, they have all maintained an exceptionally high scenic value that continues today.

Our research focuses on studying and disseminating knowledge about this patrimony.

The first step in obtaining this goal is overcoming the total lack of graphic documentation regarding the physical structure and state of preservation using a thorough three-dimensional survey. The survey was done by integrating image and range-based technologies connected to a GPS to obtain a single and georeferenced 3D model.

This digital model makes it possible to carry out a multi-scale and multi-disciplinary reading of the site.

The need to create alternative uses of the site, which are enriched by culturally oriented narrations, came from the necessity to establish new connections between the site and its surrounding community and visitors. We decided to experiment with different virtual reality options adapted to the multi-scalar dimension of the case study that includes details, site, territory and landscape.

The contemporary studies of both the remaining structure and the territorial landscape became particularly significant in this study of the Maletto Castle. The significance is due to it being part, as previously written, of the system of castles from the era of King Frederick II all around the Etna Volcano.

It was necessary to expand the section of territory to digitally represent, using DTM from regional Lidar survey campaigns or web-based models.

The modelling process used various procedures and technological resources. Their fields of application and reciprocal compatibility were tested as they needed to be combined into a single 3D digital model.

\subsection{Integrated Survey of the Site}

The choice for the most suitable surveying techniques for the castle and rock of Maletto was made taking into account the site's planimetric and altimetric layout (Figure 2).

Significant limitations derive from the steep orography of the site, which presents accentuated differences in level (Figure 3). It is, therefore, extremely challenging to position the instrument safely on the ground.

For these reasons, the integrated survey campaign involved two phases to overcome these limitations and guarantee a complete acquisition of the site's morphology.

The first phase involved a terrestrial 3D laser scanner and a GPS system applied to all the areas (even partially hidden) that could be reached by positioning the instrument along the wooden stairway and its platform at the top.

A time of flight laser scanner, Leica Scan Station C10, and a GNNS system, Leica Viva Gs15 in RTK modality, were used.

A second phase involved an aerial photogrammetric technique by drone (Parrot Anafi) and a GPS technology.

The aerial survey campaign was performed during two separate flights. After the placement of various markers and the recording of their GPS coordinates, the first overflight covered the entire site with zenithal aerial shots, following a 'grid' trajectory at a constant altitude of roughly 20 meters. 


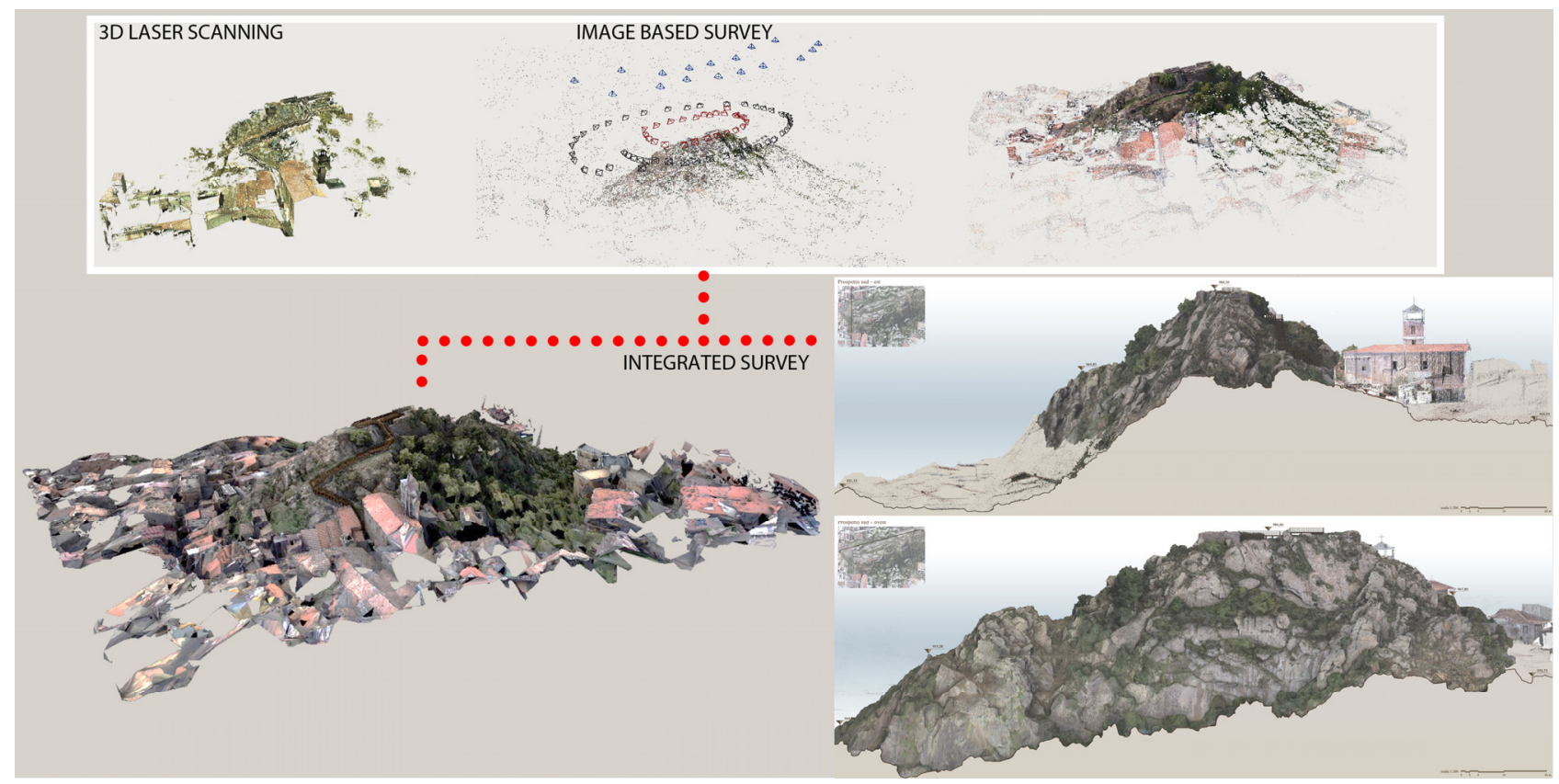

Figure 2. Maletto Castle. Integrated survey of the site.

The second flight phase involved a flyover of the top of the rock, acquiring frames with an inclination of about $50^{\circ}$ with respect to the horizontal. Special attention was placed during both flights on providing a significant overlap (both frontal and side) of the images, never less than $80 \%$.

\subsection{Data Processing Phase}

Data processing was performed in several phases. The first two phases involved, respectively, the registration of data from the terrestrial laser scanner and the photomodelling of the aerial images, both of which made it possible to obtain a partial point cloud model of the site. The third phase involved the integration and optimisation of these two different point cloud models (Figure 2).

The registration of the point clouds from the 3D laser scanner was carried out by associating the position of the high reflectance targets used in the survey campaign with the relative GPS coordinates, which allowed the point cloud to be georeferenced correctly in UTM33-WGS84. Using Cyclone Leica software, a cloud-to-cloud optimisation of the scans completed the first phase.

The processing of the images captured by the drone was developed using digital photogrammetry software (Zephyr Aerial). After uploading the calibration data from the camera used, a scattered point cloud was processed and the GPS coordinates of the markers were introduced to obtain a 3D model in the same UTM33 -WGS84 system. Once we verified the coherence of the data, the dense point cloud was generated. The last phase of data integration was carried out using the same photomodelling software, into which the TLS point cloud was also imported. The superimposition of the two point cloud models in the same reference system revealed a deviation between the homologous points' coordinates by a couple of centimetres. These differences can be attributed to the precision range of the GPS positioning and the photomodelling technique. A cloud-to-cloud optimisation phase of the point cloud models was initiated to take advantage of the more metrically correct cloud acquired by laser scanning.
Finally, the chromatic data from the terrestrial scans were corrected using the images acquired by drone, which were of superior quality.

We thus obtained a single integrated point cloud model with controlled and optimised metric and chromatic characteristics (Figure 2).

\subsection{Modelling Phase}

A 3D modelling procedure was developed through the methodological approach. The aim was to obtain a suitable result for each type of morphology present. Starting from the point cloud model, the semi-automatic process of mesh creation, in this case, led to a coherent result for the castle and rock system.

It was not, however, a satisfactory result for the small geometric elements or for those partially covered by vegetation, such as the system of stairs and platforms that allowed us access to the site.

The entire point cloud model was analysed and subdivided into geometric-semantic layers. The layer of the current access system to the site was removed.

A mesh was generated from the residual portion of the point cloud and excluded any gaps or deformations of bulb, nonmainfold, or spike typology (Di Miceli et al., 2018), related to the removed elements.

The digital removal of the wooden access stairs did not make sufficiently visible sections of the underlying original stone staircase. It was, therefore, decided to reinsert the wooden structure. Relative 3D data were imported into the BIM Revit software, to recreate its solid geometry. For research purposes, any deformations or degradations of the elements of the staircase's wooden structure were considered irrelevant and therefore not modelled.

Finally, the BIM model of the staircase system was correctly placed on the mesh model of the Maletto Castle, with the aid of the geolocated homologous points.

The final model is complete and consistent with the surveyed data, but de-contextualised. 


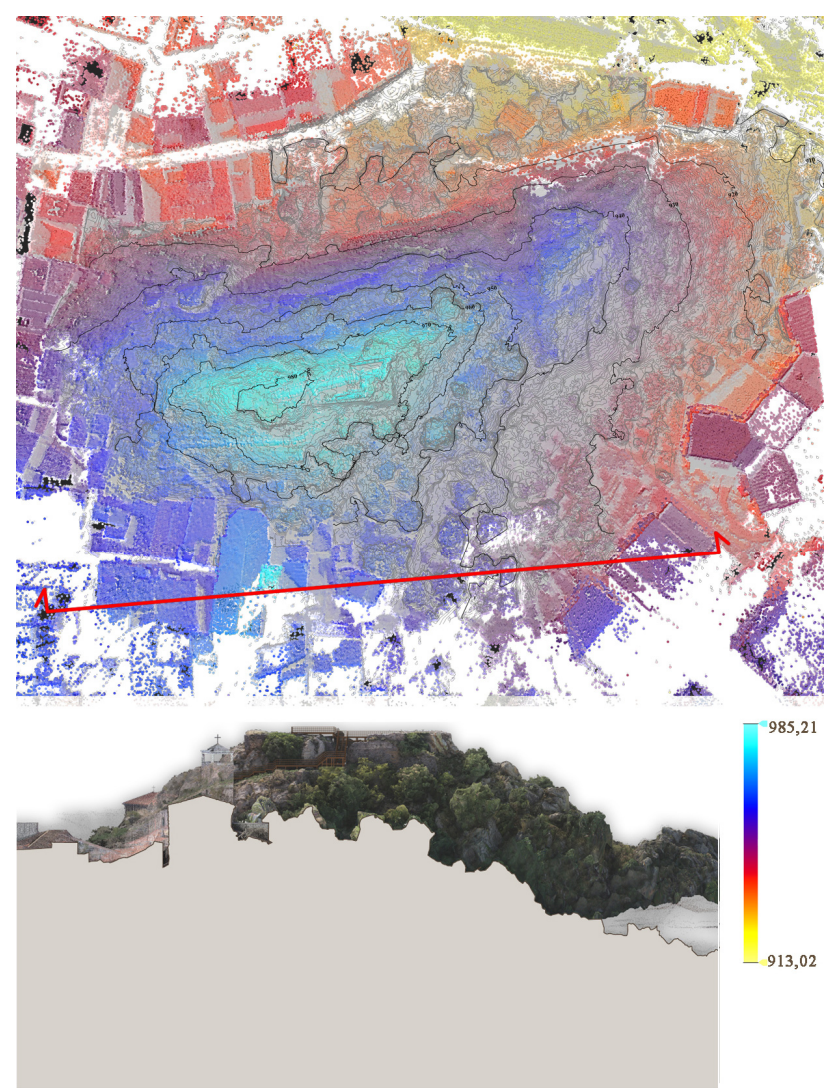

Figure 3. Maletto Castle. Planimetric and altimetric readings of the site

The next step of the experimentation, therefore, concerned the reconstruction of the broader territorial context. We achieved this thanks to LIDAR models and the ATA 2012-13 orthophotos provided by the Sicilian Region.

By using the Meshlab open-source software, a mesh surface of the entire territorial area visible from the castle was generated and textured using the metric orthophotos. The nearby landscape was also enriched by non-textured volumetric modelling of the town of Maletto, up to a distance of $5 \mathrm{~km}$.

We assembled the various parts of the model obtained into a software platform oriented to real-time rendering (static and dynamic) and virtual reality (Figure 4).

\subsection{Virtual Reality Phase}

Mixed reality is an increasingly large-scale IT product, both for its ease of use and for the many fields of application.

An example of a field of application is the protection and enhancement of cultural heritage. For instance, many museums, since the 1990s, have enhanced the physical experience of inperson visits with digital tools (e.g. Louvre Museum, Vatican Museums, Egyptian Museum of Turin) while some have completely replaced these in-person visits in favour of virtual ones (e.g. Universal Museum of Art UMA, active since 2017 and Google Art Project, active since 2011).

At the basis of these digital experiences is a twofold need: to promote and protect the cultural heritage by encouraging virtual tourism and to provide a historical record of the heritage site at a given moment.

Mixed reality can be categorised into augmented and virtual reality, depending on how it relates to the physical world.
If the experience excludes the real world by replacing it with a completely digital experience, it is considered a virtual reality. If, on the other hand, it exploits real-world reality by enhancing it within a digital context, it is augmented reality.

Both possibilities provide different types of experiences for the user based on the movement the user is free to do.

The most common virtual tour consists of the user navigating by jumping from one point to another with reduced mobility. On one hand, this mode creates a limitation, preventing the user to have a free experience. On the other hand, it makes navigation easy for users who lack specific know-how. The contents are easily accessible, clear, expandable, and enjoyable for all.

In the case study of the Maletto Castle, mixed reality lends itself well to enhancing the experience of in-person visitors, and at the same time, enhancing the virtual experience for users who are unable to visit the site due to its complex accessibility.

To simplify the use of the final application, we preferred to focus our development on virtual reality with reduced mobility (Figure 4).

With the use of Twinmotion software from Epic Games, it was possible to extrapolate high-resolution (8K) spherical equirectangular renderings, enriching them with a realistic setting (sunlight, ambient light, atmospheric cap).

The online virtual tour platform Kuula used these renderings to create a virtual walkthrough, where additional informative tags were added. This creates a tour that is enhanced with extra information about the site through drawings, photographs, and information. For example, there is added information related to the historical stratifications of the castle's remains, the morphological consistency of the cliff (Figure 4), historical information on the town of Maletto and even information on the location, history and architecture of the other medieval castles along the Etna Route (Figure 5).

\section{CONCLUSIONS}

The experimental activity carried out on the castle and rock of Maletto achieved some interesting results and triggered some reflections for the future.

The first complete and reliable graphic documentation of the site was obtained. These technical drawings don't allow us to hypothesise the original configuration of the fortified system, of which too few traces remain, but they are the first necessary documentation for the planning of possible restoration work on the walls and consolidation of the rocky ridge. They are also a fundamental step in breathing new life into the site and understanding its significant cultural, landscape, and environmental values.

The application of virtual reality should be evaluated according to two goals. One is to allow everyone the opportunity to visit the area, albeit virtually, thus overcoming the existing limits of accessibility. The second is to serve as a practical tool to identify the potentiality and limits of the site, on which to verify hypothetical interventions to improve accessibility, use, and enjoyment.

A further result concerns an extension of the model that made it possible to investigate the remaining details and the site's relationship with the surrounding landscape on a large and small scale.

With this in mind, it is fundamental to use the same methodological approach on other fortified sites through out our territory. They must be not seen as worthless and abandoned monuments but as nodes in a system of historical, cultural, and landscape relations of great interest. 


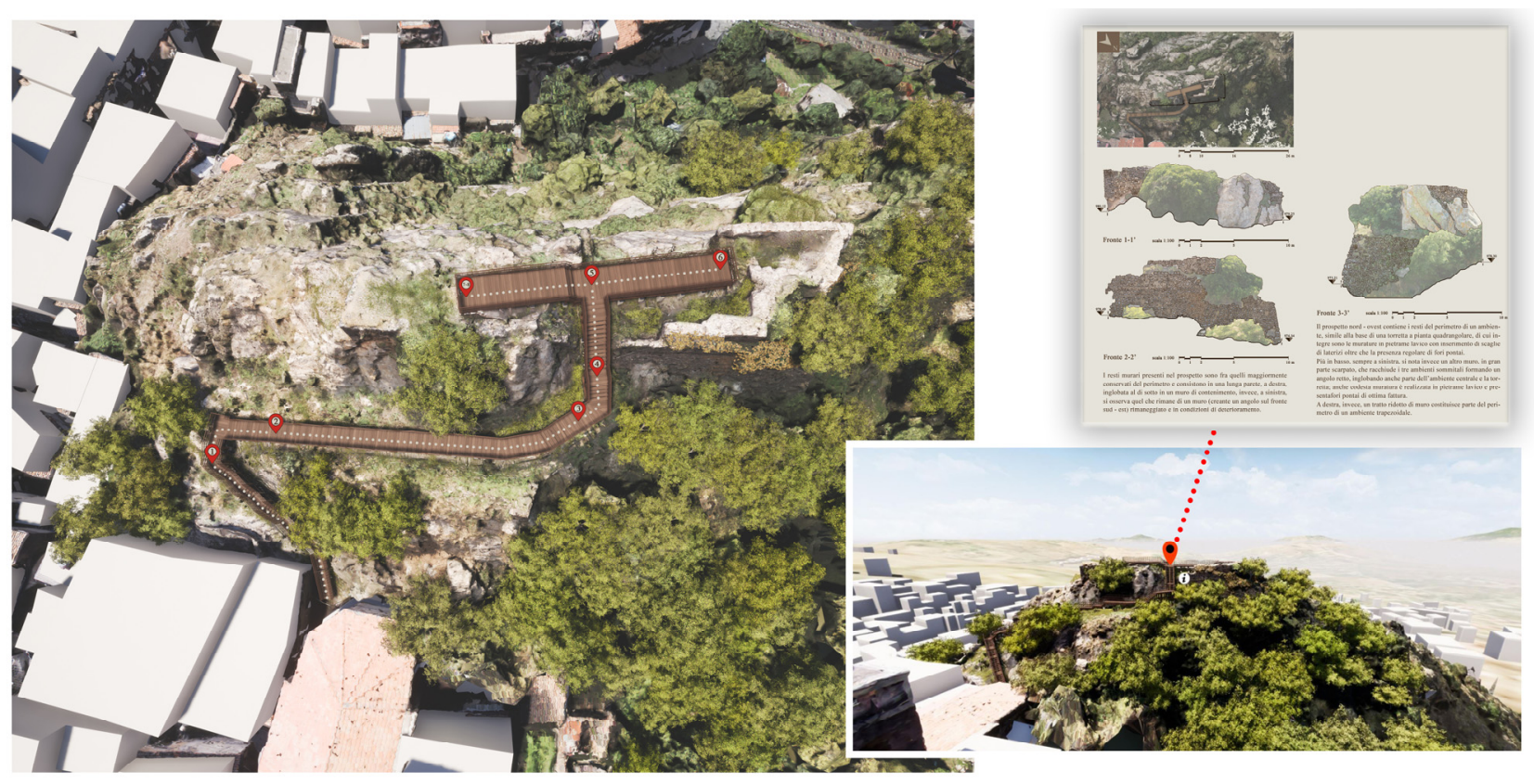

Figure 4. Maletto Castle. Smart navigation and interactive query of the 3D model

We, therefore, adopted an operational protocol characterised by the use of advanced technologies that require limited resources in terms of time and money.

This makes it an easily replicable and valuable tool to overcome the current enormous difficulties of management, safety, and enhancement of these widespread cultural and natural resources.

\section{ACKNOWLEDGEMENTS}

The study was conducted by the Survey and Representation Laboratory of Kore University of Enna, Italy, by Mariangela Liuzzo (project leader), Dario Caraccio, Egidio Di Maggio and Gianpaolo Luca.

CREDITS: M. Liuzzo: sections 1, 2, 4 and 5; G. Luca: section 3; D. Caraccio: sections 4.1 and 4.2; G. Luca and E. Di Maggio: section 4.3; E. Di Maggio: section 4.4

\section{REFERENCES}

Alibrandi, A., Signorello, L., 1988. Dei Castelli e delle Torri: note ed immagini delle fortificazioni etnee. Tip. Lombardo \& Licciardello, Misterbianco, Catania, Italy.

Canciani, M., Conigliaro, E., Del Grasso, M., Papalini, P., Saccone, M., 2016. 3D Survey and Augmented Reality for Cultural Heritage. The Case Study of Aurelian Wall at Castra Praetoria in Rome. Int. Arch Photogramm. Remote Sens. Spatial Inf. Sci., XLI-B5, 931-937. doi.org/10.5194/isprs-archives-XLIB5-931-2016

Di Miceli, G., Di Maggio, E., Lo Sciuto, G. 2018. Il combine modeling come strumento di lettura temporale dei beni culturali. In $3 D$ Modeling \& BIM, $2^{\circ}$ ed., DEI Editore, Roma, Italy, 478-497. ISBN 9788849619416

Girelli, V.A., Borgatti, L., Dellapasqua, M., Mandanici, E.,
Spreafico, M. C., Tini, M. A., Bitelli, G., 2017. Integration of Geomatics Techniques for Digitizing Highly Relevant Geological and Cultural Heritage Sites: The Case Of San Leo (Italy). Int. Arch Photogramm. Remote Sens. Spatial Inf. Sci., XLII-2/W5, 281-286. doi.org/10.5194/isprs-archives-XLII-2W5-281-2017, 2017

Helle, S, Lehtonen, T., Woodward, C., Turunen, M., Salmi, H., 2017. Miracle handbook guidelines for mixed reality applications for culture and learning experiences, University of Turku, Finland. ISBN:9789512968848

Herrero-Tejedor, T.R., Arqués Soler, F., López-Cuervo Medina, S., de la O Cabrera, M.R., Martín Romero, J.L., 2020. Documenting a cultural landscape using point-cloud $3 d$ models obtained with geomatic integration techniques. The case of the El Encin atomic garden, Madrid, Spain. PLoS ONE 15(6): e0235169. doi.org/10.1371/journal.pone.0235169

Jo, Y.H., Kim, J.Y., 2017. Three-Dimensional Digital Documentation Of Heritage Sites Using Terrestrial Laser Scanning And Unmanned Aerial Vehicle Photogrammetry. Int. Arch Photogramm. Remote Sens. Spatial Inf. Sci., XLII-2/W5, pp. 395-398. doi.org/10.5194/isprs-archives-XLII-2-W5-3952017

Liuzzo, M., Brienza, E., Giuliano, S., 2017. Integrated survey techniques for archaeological frameworks and context documentation: methodological notes for a multi-scale approach. DISEGNARECON, 10 (19), 3.1-3.18. ISSN 18285961

Liuzzo, M., Giuliano, S., 2019. La modellazione dei sistemi urbani nel rapporto tra elementi antropici e naturali. Centri Urbani documentazione e prospettive di sviluppo, $P h D$ Kore Review, 12, special issue, Euno Edizioni, Leonforte (EN), Italy, 39-53. ISSN 2039-5434 

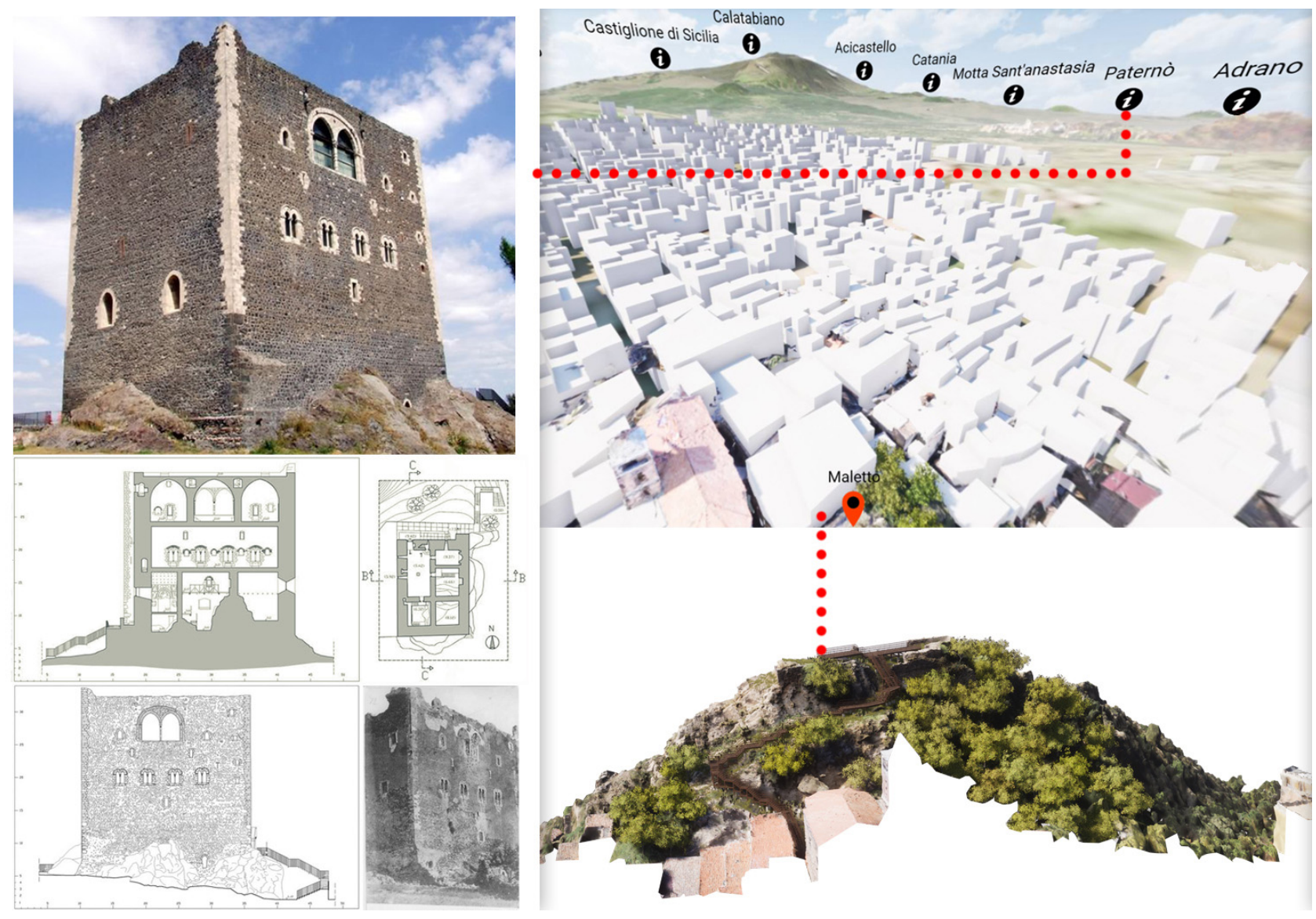

Figure 5. Maletto Castle and the other fortifications of the Etna Route. Smart navigation and interactive query of the 3D model

Liuzzo, M., Feo, R., Giuliano, S., Pampalone, V., 2019. A Combined Approach For Surveying Complex Coastal Sites. Int. Arch. Photogramm. Remote Sens. Spatial Inf. Sci., XLII-2/W9, 425-432. doi.org/10.5194/isprs-archives-XLII-2-W9-425-2019

Liuzzo, M., Caraccio, D., Di Maggio, E., Alessandra, F., 2020. From the integrated survey to the virtual enjoyment of the ruined, fortified Sites. The case study of the Castle of Nicosia (Enna). In Barba S., Limongiello M., Parrinello S., Dell'Amico A. (ed.), D-SITE Drones - Systems of Information on cuTtural Heritage. For a spatial and social investigation, Edizioni Pavia University, Italy, 40-49. ISBN 9788869521201

Mongiello, G., Verdoscia, C., Tavolare, R., Angiulli, M.T., 2018. Augmented Reality with Google Project Tango for the representation of 3D digital architectural models in real space. $3 D$ Modeling \& BIM, $2^{\circ}$ ed., DEI Editore, Roma, Italy, 442453. ISBN 9788849619416

Nibali, S, and Luca. G.M. 1983. Maletto, memorie storiche. Grafica 77, Catania, Italy

Remondino, F., 2011. 3D surveying and modelling of complex architectural sites and heritage objects. DISEGNARECON, 4(8), 90-98. doi.org/10.6092/issn.1828-5961/2573

Spallone, R., Lamberti, F., Guglielminotti Trivel, M., Ronco, F., Tamantini, S., 2021. 3d Reconstruction and Presentation of Cultural Heritage: AR and VR Experiences at the Museo d'Arte Orientale di Torino. Int. Arch Photogramm. Remote Sens.
Spatial Inf. Sci., XLVI-M-1-2021, 697-704. doi.org/10.5194/isprs-archives-XLVI-M-1-2021-697-2021

Teruggi, S., Grilli, E., Fassi, F., Remondino, F, 2021. 3d Surveying, Semantic Enrichment And Virtual Access Of Large Cultural Heritage. ISPRS Annals of the Photogrammetry, Remote Sensing and Spatial Information Sciences, VIII-M-12021, 158-162.doi.org/10.5194/isprs-annals-VIII-M-1-2021$155-2021$

Valenti, R., Paternò, E., 2021. 3D Integrated Survey for the Study of Archaeological Sites: the Case Study of Euryalus Castle in Siracusa. IOP Conf. Ser.: Earth and Environmental Science 767 (2021) 012015, 1-8. doi.org/10.1088/17551315/767/1/012015

Versaci, A., Fauzìa, L. R., Russo, M., Cardaci, A., 2020. The integrated fast survey for the risk assessment: a proposal for the safeguarding of the medieval castles in central Sicily, Int. Arch. Photogramm. Remote Sens. Spatial Inf. Sci., XLIV-M-1, 893900. doi.org/10.5194/isprs-archives-XLIV-M-1-2020-893-2020

Zara, J. 2004. Virtual Reality and Cultural Heritage on the Web. In Proceedings of the 7th International Conference on Computer Graphics and Artificial Inteligence (3IA 2004), Limoges, France, 101-112. ISBN 291425606X 